\title{
Anti-DNA Antibody Production by CD5+ and CD5- B Cells of Patients with Systemic Lupus Erythematosus
}

\author{
Noboru Suzuki, Tsuyoshi Sakane, * and Edgar G. Engleman \\ Department of Pathology, Stanford University, Stanford, California 94305; and *Department
}

of Internal Medicine, Shimane Medical University, Izumo, Shimane 693, Japan

\begin{abstract}
Although the presence of anti-DNA antibody is a hallmark of systemic lupus erythematosus (SLE), neither the subsets of B cells that secrete anti-DNA antibody nor the stimuli responsible for the induction of anti-DNA secretion is known. In particular, the role of CD5+ B cells in human SLE, a distinct subpopulation of antibody-secreting cells shown previously to be a source of anti-DNA antibody in murine models of SLE, is unknown. To approach these questions, we developed a sensitive enzyme-linked immunospot (ELIspot) assay to measure spontaneous secretion of antibody to single-stranded (ss) DNA, double-stranded (ds) DNA, tetanus toxoid, and polyclonal immunoglobulin (Ig) by purified CD5+ and CD5- B cells of 15 SLE patients and 15 healthy control subjects. The B cells of only 1 of 15 healthy subjects secreted a significant level of anti-ssDNA antibody, and none secreted anti-dsDNA. By contrast, in the majority of SLE patients both CD5+ and CD5- B cells secreted IgG and/or IgM anti-ssDNA as well as antidsDNA antibody. Further analysis of the anti-ssDNA response revealed that the level of IgG and IgM anti-DNA antibody secretion by CD5- B cells correlated closely with the level of polyclonal Ig production by the same subpopulation ( $r$ $=0.81$ and 0.70 , respectively). In contrast, production of antiDNA by CD5+ B cells occurred independently of polyclonal Ig production by both CD5+ and CD5- B cell subpopulations. These results suggest that in human SLE there exist two antiDNA antibody-producing B cell subpopulations with distinct induction mechanisms: one (CD5 + ), which independently secretes anti-DNA, and another (CD5-), which produces antiDNA as an apparent consequence of polyclonal $B$ cell activation. (J. Clin. Invest. 1990. 85:238-247.) anti-DNA antibody • CD5+ B cells - CD5- B cells • polyclonal B cell activation • systemic lupus erythematosus
\end{abstract}

\section{Introduction}

Systemic lupus erythematosus (SLE) ${ }^{1}$ is a multisystem disease of unknown etiology characterized by aberrant immune regulation and excessive production of multiple autoantibodies

Address reprint requests to Dr. Suzuki, Stanford University Blood Center, 800 Welch Road, Palo Alto, CA 94304.

Received for publication 31 March 1989 and in revised form 10 August 1989.

1. Abbreviations used in this paper: dsDNA, double-stranded DNA; ELIspot assay, enzyme-linked immunospot assay; SAC I, Staphylococcus aureus Cowan I; ssDNA, single-stranded DNA; TT, tetanus toxoid.

J. Clin. Invest.

(C) The American Society for Clinical Investigation, Inc.

0021-9738/90/01/0238/10 \$2.00

Volume 85, January 1990, 238-247
(1-8). In spite of extensive studies of both SLE patients and mouse models of lupus-like disease, considerable controversy remains as to whether excess autoantibody production reflects specific stimulation of autoreactive clones (as in a response to specific and/or cross-reactive antigen) $(3,9)$ or polyclonal activation of many different B cells (10-12). The model of selective B cell activation is supported by several findings: $(a)$ there is a disproportionate increase in the concentration of antibodies to a few selected autoantigens in the sera of most autoimmune patients and mice $(13,14) ;(b)$ B cells capable of autoantibody production selectively and rapidly expand when transferred from autoimmune mice to B cell-depleted recipient mice (15); and (c) most of the antibody responses in a chronic graft-versus-host F1 model of SLE are not random but, rather, specific to the autoantigens present at the initiation of the disease (16). However, numerous lines of evidence also support an etiologic role for polyclonal $B$ cell activation in SLE. For example, (a) B cell hyperresponsiveness and spontaneous polyclonal activation are invariably present in both SLE patients and animal models of SLE $(1,19-21) ;(b)$ activation of B cells, in vitro or in vivo, with polyclonal stimulators results in production of a variety of autoantibodies similar to those found in SLE $(22,23)$; (c) chronic polyclonal activation in genetically nonautoimmune mice can cause autoimmune disease (24); and $(d)$ genetic studies indicate an intrinsic B cell abnormality in several autoimmune strains of mice that is linked to polyclonal B cell hyperactivity $(1,25)$.

The recent discovery that most autoantibodies produced by mice with genetically determined autoimmune disease are derived from B cells expressing the CD5 (Ly1) antigen $(17,18)$ offers an exciting new avenue for investigation into the pathogenesis of human autoimmune disease. CD5+ B cells have been found in high numbers in fetal spleen, chronic lymphocytic leukemia, recipients of bone marrow allografts, and patients with rheumatoid arthritis. A variety of studies suggest that human CD5 + B cells constitute a distinct B cell lineage, homologous functionally and phenotypically to mouse Ly $1+$ B cells (26-34). Moreover, upon in vitro stimulation with polyclonal activators, $\mathrm{CD} 5+\mathrm{B}$ cells produce autoantibodies similar to those seen in rheumatoid arthritis and $\operatorname{SLE}(27,28)$.

Despite these provocative findings, a role for CD5+ B cells in the production of anti-DNA antibody in SLE has not yet been demonstrated. In an effort to explore this question, we used a sensitive assay to measure the spontaneous production of anti-DNA antibody by CD5+ and CD5- B cells obtained from patients with SLE. The results indicate that both CD5+ and CD5- B cells produce anti-DNA antibody. However, CD5- B cells appear to produce anti-DNA as a consequence of polyclonal activation, in vivo, whereas CD5 + B cells do not.

\section{Methods}

Patient selection. We studied 15 patients, all women, who fulfilled American Rheumatism Association criteria for the diagnosis of SLE 
(35). The mean age $( \pm \mathrm{SD})$ of these patients was $33.7 \pm 10.7 \mathrm{yr}$ (range 19-56 yr) (Table I). Disease activity was assessed at the time of phlebotomy on the basis of clinical and laboratory findings (fever, arthralgias, rash, oral ulcers or alopecia, elevated erythrocyte sedimentation rate $(>30 \mathrm{~mm} / \mathrm{h})$, leukopenia $(<4,000 / \mu \mathrm{l})$, hypoalbuminemia $(<3.5$ $\mathrm{g} / \mathrm{dl})$, hypocomplementemia $\left(\mathrm{CH}_{50}<20 \mathrm{U} / \mathrm{ml}\right)$, and presence of antinuclear antibody (titer $>1: 80$ ) (36). Seven patients with three or more of these criteria were categorized as active; eight patients with two or fewer criteria of activity were included in the inactive group. At the time of study seven patients were receiving no treatment, five were receiving low-dose corticosteroid therapy (prednisone $5-10 \mathrm{mg} / \mathrm{d}$ ), two patients were receiving intermediate-dose prednisone $(15 \mathrm{mg} / \mathrm{d})$, and one patient was on high-dose prednisone $(40 \mathrm{mg} / \mathrm{d})$ (Table I). One patient had received total lymphoid irradiation 3 yr before the study. No patients were receiving cytotoxic drugs at the time of study.

15 healthy volunteer blood donors ( 12 women and $3 \mathrm{men}$ ) served as control subjects. Their mean age $( \pm \mathrm{SD})$ was $37.7 \pm 11.8$ yr (range 23-61 yr).

Cell separation. Peripheral blood mononuclear cells were separated into $T$ and non-T enriched fractions with a sheep erythrocyte rosetting technique (36). Monocytes were depleted from the non-T cell fraction by adherence on plastic petri dishes $(37,38)$. The remaining non-T, nonadherent cells were further depleted of residual T cells, NK cells, and monocytes by panning with OKT3, Leu $11 \mathrm{c}$, and Leu M3 monoclonal antibodies, respectively (39). The resultant B cell enriched population contained $<0.5 \%$ OKT $3+$ cells, $<1 \%$ Leu M3+ cells, $<2 \%$ Leu $11 \mathrm{c}+$ cells, and $>90 \%$ cells bearing surface membrane Ig on the basis of indirect immunofluorescent analysis on an cytofluorograf (system $50 \mathrm{H}$, Ortho Diagnostics, Westwood, MA).

B cells were separated into CD5+ and CD5- subpopulations by panning with anti-Leu 1 (anti-CD5) antibody (36). Briefly, B cells enriched as above were incubated with anti-Leu 1 antibody for $1 \mathrm{~h}$ at $4^{\circ} \mathrm{C}$. After washing, the cells were incubated for $90 \mathrm{~min}$ at $4^{\circ} \mathrm{C}$ in plastic petri dishes previously coated with $10 \mu \mathrm{g} / \mathrm{ml}$ affinity purified goat anti-mouse IgG antibody (Zymed Laboratories, San Francisco, CA). The nonadherent cells were gently recovered and washed extensively before use. The dishes were washed three times in cold PBS, and adherent cells were harvested after an additional $30 \mathrm{~min}$ incubation at $37^{\circ} \mathrm{C}$ in the presence of RPMI 1640 medium containing $10 \%$ FCS. The resultant Leu $1+(\mathrm{CD} 5+)$ fraction and Leu $1-(\mathrm{CD} 5-)$ fraction contained $>90 \%$ CD5 + B cells and $>95 \%$ CD5 - B cells, respectively.

This procedure yielded $1.1 \pm 0.3 \times 10^{6} \mathrm{CD} 5+$ and $4.0 \pm 1.0 \times 10^{6}$ CD5 - B cells from healthy subjects, and $0.8 \pm 0.2 \times 10^{6} \mathrm{CD} 5+$ and $2.6 \pm 1.1 \times 10^{6} \mathrm{CD} 5-\mathrm{B}$ cells from SLE patients per $60 \mathrm{ml}$ of peripheral blood. Thus, while the absolute numbers of both $B$ cell subpopulations are reduced in our SLE cohort, the proportions of CD5+ and CD5- B cells in the SLE and healthy cohorts are similar, consistent with previous reports that $\mathrm{CD} 5+\mathrm{B}$ cells are not increased in the peripheral blood of SLE patients $(34,36)$.

Induction of antibody secretion with mitogen stimulation. In some experiments, B cells were stimulated in vitro with Staphylococcus aureus Cowan I (SAC I) before assay for antibody production. In these experiments, $2 \times 10^{5} \mathrm{CD} 5+$ or CD5- B cells were cultured in the presence of 0.002\% SAC I (Pansorbin; Behring Diagnostics, La Jolla, CA), and a 48 h supernatant of PHA stimulated T cells $(32,33)$. Triplicate cultures were incubated at $37^{\circ} \mathrm{C}$ in a final volume of $1 \mathrm{ml}$ in 48-well flat-bottomed plates (Costar, Cambridge, MA), harvested after $6 \mathrm{~d}$, then washed three times in Dulbecco's modified Eagle's media (DME; Gibco Laboratories, Grand Island, NY), and assayed for antibody secreting cells. B cell subpopulations were tested for cell surface antigens postactivation and both populations were found to maintain the phenotype for which they were initially selected (data not shown). In another experiment, peripheral blood lymphocytes (PBL) were activated by $0.002 \%$ SAC I or $1 \mu \mathrm{g} / \mathrm{ml}$ pokeweed mitogen (PWM, Gibco) for $\mathbf{6} \mathrm{d}$ and assayed for antibody secretion.

Reagents and monoclonal antibodies. Single-stranded (ss) DNA was obtained by heat denaturation of double-stranded (ds) DNA, which had been prepared by digestion of calf thymus DNA (Worthington Biochemicals, Freehold, NJ) with $1,000 \mathrm{U} / \mathrm{ml}$ of $\mathrm{S} 1$ nuclease (Sigma Chemical Co., St. Louis, MO), followed by fractionation on a DNA grade hydroxyapatite column (Bio-Rad Laboratories, Richmond, CA) (40). Mouse monoclonal antibodies used in this study were produced and purified in our laboratory and used as described elsewhere (41) for cell purification and surface phenotype analysis.

Table I. Patient Profile and Spontaneous Antibody Production

\begin{tabular}{|c|c|c|c|c|c|c|c|c|c|c|c|c|}
\hline \multirow{2}{*}{$\begin{array}{l}\text { Patient } \\
\text { No. }\end{array}$} & \multirow[b]{2}{*}{ Age } & \multirow{2}{*}{$\begin{array}{l}\text { Disease } \\
\text { activity* }\end{array}$} & \multirow{2}{*}{$\begin{array}{l}\text { Disease } \\
\text { duration }\end{array}$} & \multirow{2}{*}{$\begin{array}{l}\text { Drug } \\
\text { dose }\end{array}$} & \multicolumn{2}{|c|}{ Total IgM production ${ }^{\ddagger}$} & \multicolumn{2}{|c|}{ Total IgG production } & \multicolumn{2}{|c|}{ IgM anti-ssDNA production } & \multicolumn{2}{|c|}{ IgG anti-ssDNA production } \\
\hline & & & & & CD5+ B cells & CD5- B cells & CD5+ B cells & CD5- B cells & CD5+ B cells & CD5- B cells & CD5+ B cells & CD5- B cells \\
\hline & & & & $m g / d$ & & & & & & & & \\
\hline 1 & 42 & Inactive & $12 \mathrm{yr}$ & PSN $5^{\prime \prime}$ & 5,200 & 2,500 & 5,500 & 17,500 & $\mathrm{NS}^{\S}$ & 95 & NS & 127 \\
\hline 2 & 25 & Active & $7 \mathrm{yr}$ & None & 2,000 & 1,800 & 5,400 & 23,000 & NS & NS & NS & 200 \\
\hline 3 & 30 & Inactive & $3 \mathrm{yr}$ & PSN 10 & 1,100 & 900 & 1,200 & 1,300 & NS & NS & NS & NS \\
\hline 4 & 26 & Active & $3 \mathrm{yr}$ & PSN 15 & 5,400 & 7,900 & 4,050 & 4,100 & 100 & 100 & 40 & NS \\
\hline 5 & 45 & Inactive & $10 \mathrm{yr}$ & None & 5,000 & 2,167 & 6,400 & 3,300 & NS & NS & 120 & NS \\
\hline 6 & 46 & Inactive & $7 \mathrm{yr}$ & PSN 10 & 4,400 & 2,467 & 21,800 & 8,900 & 80 & 106 & NS & 70 \\
\hline 7 & 24 & Active & $2 \mathrm{yr}$ & None & 17,200 & 3,469 & 18,500 & 5,000 & NS & 66 & 400 & 40 \\
\hline 8 & 25 & Active & $5 \mathrm{yr}$ & PSN 40 & 6,200 & 4,700 & 16,600 & 16,600 & NS & NS & 92 & 183 \\
\hline 9 & 19 & Active & $1 \mathrm{wk}$ & None & 7,000 & 3,500 & 3,500 & 4,500 & NS & NS & NS & 133 \\
\hline 10 & 24 & Inactive & $3 \mathrm{yr}$ & PSN 10 & 5,500 & 1,000 & 24,000 & 1,500 & 43 & NS & NS & NS \\
\hline 11 & 28 & Active & $1 \mathrm{wk}$ & None & 11,500 & 11,500 & 23,000 & 20,000 & 294 & 927 & 48 & 300 \\
\hline 12 & 30 & Inactive & $4 \mathrm{yr}$ & None & 1,550 & 6,500 & 2,500 & 1,500 & 80 & NS & NS & NS \\
\hline 13 & 46 & Inactive & $10 \mathrm{yr}$ & PSN 10 & 2,850 & 7,250 & 4,700 & 17,000 & 50 & NS & 30 & 60 \\
\hline 14 & 40 & Active & $1 \mathrm{wk}$ & None & 6,250 & 10,000 & 4,500 & 18,000 & 550 & 260 & 100 & 130 \\
\hline 15 & 56 & Inactive & $20 \mathrm{yr}$ & PSN 15 & 4,000 & 4,950 & 4,800 & 3,000 & NS & NS & NS & NS \\
\hline
\end{tabular}

* Disease activity was assessed at the time of phlebotomy by the criterion described in Methods. ${ }^{\ddagger}$ Spontaneous antibody production was measured by ELIspot assay described in Methods. Each value represents the mean number of spots $/ 10^{6} \mathrm{~B}$ cells tested. ${ }^{8} \mathrm{NS}$, anti-ssDNA $<$ mean +2 SD of 15 normal controls: IgM anti-ssDNA from CD5+ B cells, those from CD5- B cells, IgG anti-ssDNA from CD5+ B cells and those from CD5- B cells were $<29,<35,<23$, and $<30$, respectively. "PSN, prednisone. 
Preparation of antigen-coated plates. For measurement of antiDNA antibody, $100 \mu \mathrm{g} / \mathrm{ml}$ of ssDNA or dsDNA was added to 96-well microtiter plates (Immulon 1; Dynatech, Alexandria, VA) which were precoated with $0.01 \%$ methylated BSA (Sigma) and incubated overnight at $4^{\circ} \mathrm{C}$. To measure anti-tetanus toxoid (TT) antibody, 5 limes flocculation $\mathrm{U} / \mathrm{ml}$ of tetanus toxoid (Massachusetts State Department of Public Health, Jamaica Plain, MA) was dissolved in carbonate buffer and coated onto 96-well microtiter plates. In order to estimate total (polyclonal) Ig production, goat anti-human IgM or IgG (Cappel Laboratories, West Chester, PA) $(10 \mu \mathrm{g} / \mathrm{ml})$ was coated onto the plates.

ELIspot assays. Highly enriched B cell subpopulations or mitogen activated peripheral blood lymphocytes were suspended in DMEM supplemented with 3\% BSA (RIA grade, Sigma). Serial dilutions of these cell suspensions, usually starting with $2.5 \times 10^{5}$ cells/well for freshly isolated B cell subpopulations, $2 \times 10^{5}$ cells/well for SAC I stimulated B cells, and $2 \times 10^{6}$ cells/well for mitogen activated PBL, were incubated on antigen coated plates for $12-18 \mathrm{~h}$ at $37^{\circ} \mathrm{C}$ in an atmosphere of $5 \% \mathrm{CO}_{2}$ in air. As a control, cells were also incubated on plates uncoated with antigen or anti-Ig. Thereafter, the cells were removed with PBS $/ 0.05 \%$ Tween 20 and distilled water, and the plates were overlaid with biotin conjugated anti-human IgM or IgG (Kirkegaard and Perry Laboratories, Gaithersburg, MD) for overnight incubation at $4^{\circ} \mathrm{C}$. The plates were washed again and streptavidin-alkaline phosphatase (Bethesda Research Laboratories, Gaithersburg, MD) was added and the plates incubated for $1 \mathrm{~h}$ at room temperature. Antibodies produced by individual B cells that bound to the plate were visualized by addition of a solution of 5-bromo-3-chloroindolyl phosphate (Sigma) in a low gelling temperature agarose kept at $44^{\circ} \mathrm{C}$. Alkaline phosphatase acts on this substrate to produce a blue spot that cannot diffuse through the agarose once it solidifies at room temperature

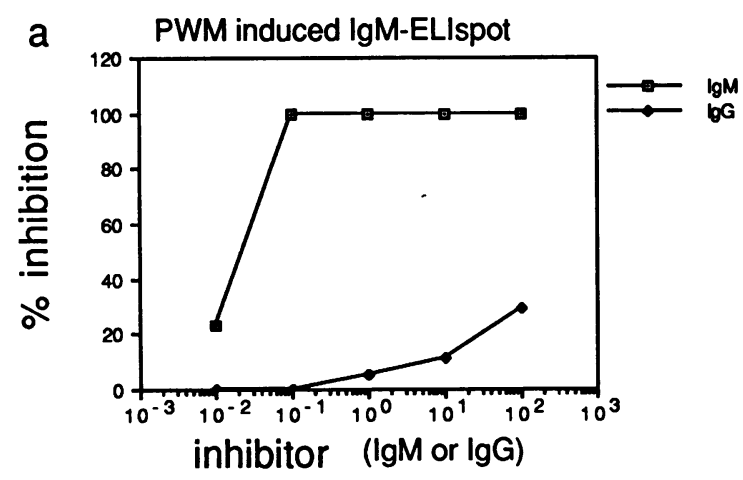

C SAC I induced IgM anti-ss DNA antibody ELIspot

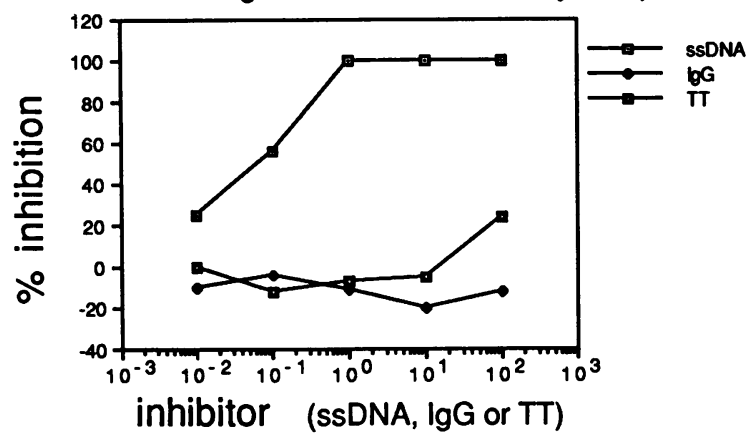

(42-45). To calculate the number of antigen-specific spots, the number of spots on antigen uncoated control wells were subtracted from the number on antigen-coated wells.

Statistical methods. Statistical significance was ascertained by the Student's $t$ test and linear regression analysis. Probability values of $>5 \%$ were considered not significant.

\section{Results}

Characterization of the ELIspot assay. Attempts to apply conventional anti-DNA ELISA (46) for measurement of spontaneous anti-DNA secretion were unsatisfactory due to inadequate sensitivity (data not shown). Therefore, we adapted the ELIspot technique, which detects individual antibody secreting cells rather than secreted antibody. The sensitivity and specificity of this assay have been documented in murine (42, $43)$ as well as human $(44,45)$ systems, and further characterized and confirmed for the antigens studied herein. If antigen or anti-Ig antibody was not coated onto the plate, spots (indicating antibody secretion) did not develop even in the presence of B cells (data not shown). In the presence of antigen, the ELIspot assay was highly specific as shown in competitive inhibition experiments (Fig. 1). For determination of isotype specificity, normal PBL activated for $6 \mathrm{~d}$ with PWM were incubated for $12 \mathrm{~h}$ on plates coated with anti-human IgM or anti-human IgG antibody. As an inhibitor, chromatography purified human IgG or IgM (myeloma derived; Jackson Immunoresearch Laboratories, Avondale, PA) was added to the well at a
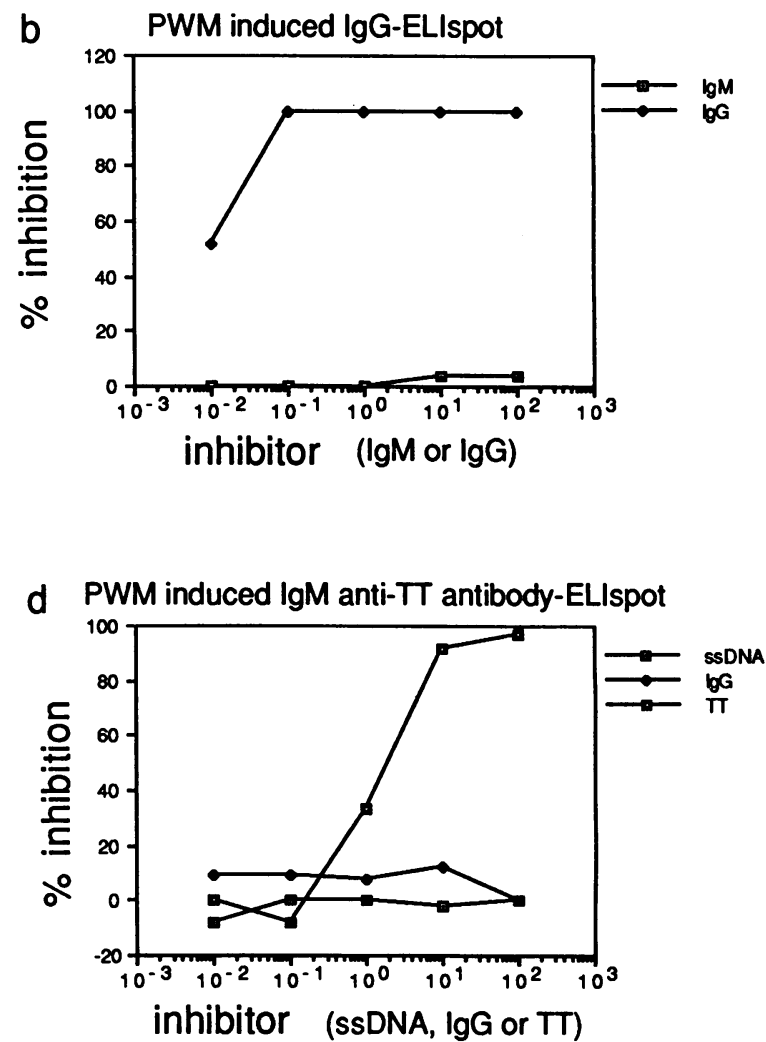

Figure 1. Isotype and antigen specificity of ELIspot assay. (a) IgM ELIspot, (b) IgG ELIspot, (c) IgM anti-DNA antibody ELIspot, (d) IgM antitetanus toxoid (TT) antibody ELIspot. Pokeweed mitogen activated $(a),(b)$, and $(d)$ or SAC I-activated normal PBL $(c)$ were used as indicator cells $(a)$ and $(b), 1 \times 10^{4}$ cells/well; $(c)$ and $(d), 2 \times 10^{6}$ cells/well. For each ELIspot assay, antigens were added in the indicated concentrations $(\mu \mathrm{g} / \mathrm{ml}$ for IgM, IgG, and ssDNA, and limes flocculation $\mathrm{U} / \mathrm{ml}$ for TT). Actual values of each positive control well were $60,52,39$, and 11 antibody-secreting cells/well for IgM, IgG, anti-DNA and anti-TT ELIspot, respectively. Results are representative of three experiments. 
concentration of $0.01-100 \mu \mathrm{g} / \mathrm{ml}$. The anti-IgM ELIspot was unaffected by IgG but was inhibited by IgM in a dose-dependent manner (Fig. $1 a$ ). Conversely, development of the antiIgG ELIspot was specifically blocked by IgG but not IgM (Fig. $1 b)$.

We next examined the antigen specificity of IgM anti-DNA and IgM anti-tetanus toxoid (TT) ELIspot assays using SAC I and PWM-activated normal PBL as indicator cells and ssDNA, TT, and human IgG as inhibitors. As shown in Fig. 1, $c$ and $d$, the anti-ssDNA and anti-TT ELIspot assays were inhibited, respectively, by ssDNA and TT in a dose-dependent fashion, but not by irrelevant antigens. Similarly, using SLE PBL and normal PBL, the specificity of IgG anti-DNA and IgG anti-TT ELIspot assays was confirmed (data not shown).

Spontaneous production of polyclonal immunoglobulin from SLE CD5+ and CD5- B cells. To determine whether CD5+ and/or CD5- B cells were responsible for the excessive production of polyclonal Ig in SLE (19-21), freshly isolated B cell subpopulations of SLE patients were cultured on antihuman IgM or IgG coated plates for $18 \mathrm{~h}$, and the number of Ig producing cells was determined by ELIspot assay (Table I and Fig. 2). Among healthy subjects, relatively low numbers of CD5+ B cells spontaneously secreted IgM or IgG (spontaneous Ig producing cells $/ 10^{6}$ B cells [mean \pm SE]; IgM, $1,278 \pm 214$; IgG, 1,028 \pm 274 ) (Fig. 2). Somewhat higher numbers of CD5- B cells from the same normal subjects produced

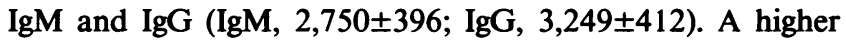
proportion of CD5+ and CD5- B cells of SLE patients spontaneously secreted both IgM and IgG than did normal controls (SLE CD5+ B cells: IgM, 5,677 $\pm 1,019$; IgG, 9,767 $\pm 2,076$;

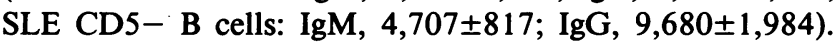
These results suggest that both CD5+ and CD5- B cells are activated in vivo in SLE patients.

Spontaneous production of anti-DNA antibody by SLE $C D 5+$ and $C D 5-B$ cells. We next examined the CD5+ and CD5- B cells from our SLE and healthy control cohorts for their spontaneous secretion of anti-ssDNA antibody. In order
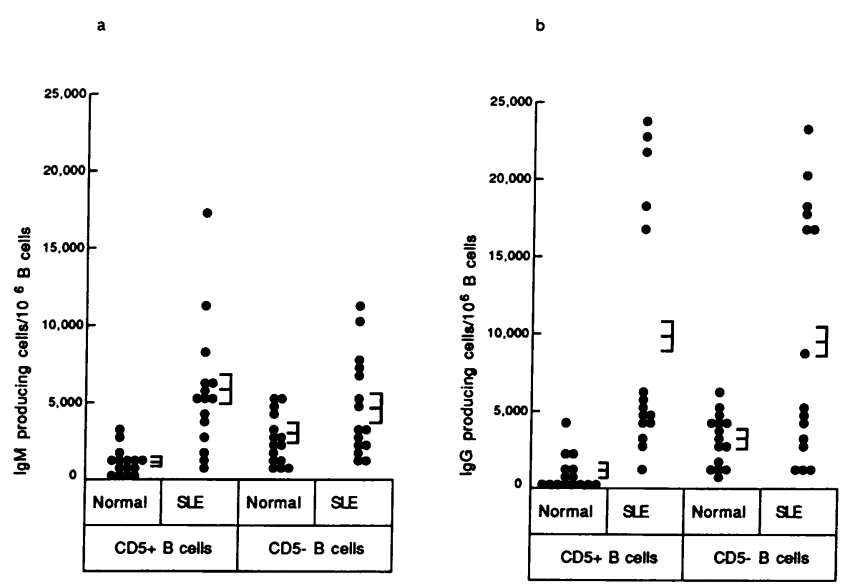

Figure 2. Spontaneous production of polyclonal immunoglobulin by SLE CD5 + B cells and CD5- B cells. Highly purified CD5+ B or CD5- B cells from SLE patients as well as normal healthy control subjects were cultured for $18 \mathrm{~h}$ in wells coated with anti-human IgM or anti-human IgG, and total Ig producing cells were determined by ELIspot assay. (a) IgM production, (b) IgG production. Brackets indicate mean \pm standard error of 15 SLE patients or 15 normal controls. to obtain information about the cellular source of antibodies to a nominal foreign antigen, we simultaneously measured the spontaneous production of anti-TT antibody by these B cell subpopulations. As shown in Fig. 3, $a$ and $b$, B cells from the majority of SLE patients secreted anti-ssDNA, whereas only a single healthy control subject had detectable anti-ssDNA secreting cells. The CD5- B cells from 6 of the 15 SLE patients studied secreted IgM anti-ssDNA antibody at levels significantly greater ( $>2$ SD) than background. The CD5- B cells from nine patients secreted significant levels of IgG antissDNA. A similar number of patients (seven for both IgM and IgG anti-ssDNA antibody) had circulating CD5+ B cells which spontaneously secreted anti-ssDNA antibody. In addition, those that did so had roughly equivalent numbers of antissDNA secreting CD5+ and CD5- B cells. Although the results shown in Table I and Fig. 3 were obtained with B cell subpopulations isolated by panning, virtually identical results were obtained in a study of CD5 + and CD5- subsets isolated to $>98 \%$ purity with a fluorescence activated cell sorter, confirming that anti-ssDNA antibody is secreted by both $B$ cell subpopulations (data not shown). In addition, we restained each B cell subpopulation after $6 \mathrm{~d}$ stimulation with SAC I and confirmed that their phenotypes corresponded to those originally selected (see below).

In addition to the studies of anti-single stranded (ss) DNA antibody production, in six patients we also studied spontaneous anti-double stranded (ds) DNA antibody production. As shown in Fig. 4, the CD5- B cells from all six patients spontaneously secreted IgG anti-dsDNA. In four of these patients both the CD5+ and CD5- B cells produced IgM as well as IgG anti-dsDNA antibody. As shown in the same figure, the CD5+ and CD5- B cells from healthy subjects did not secrete any detectable anti-dsDNA antibody. The possibility exists that some of the dsDNA denatured upon fixation to the ELISA plates and what appears as anti-dsDNA antibody, in fact, represents anti-ssDNA antibody. However, addition of dsDNA to the anti-dsDNA ELIspot assay inhibited the assay, whereas ssDNA did not (data not shown), confirming the specificity of the assay. On this basis, we conclude that CD5+ and CD5- B cells from SLE patients secrete anti-dsDNA as well as antissDNA antibodies.

In results similar to those for anti-DNA secreting cells, the majority of SLE patients had circulating B cells that spontaneously secreted antibody to TT, whereas normal subjects did not (Fig. 3, $c$ and $d$ ). However, in contrast to anti-DNA, antiTT antibody was produced almost exclusively by CD5- B cells from these patients, and consisted almost entirely of immunoglobulin of IgM isotype. The absolute number of IgM anti-TT antibody secreting CD5- cells was slightly lower than that of IgM anti-ssDNA antibody secreting CD5- cells from the same patients $\left(60.9 \pm 31.3\right.$ vs. $113.4 \pm 58.6 / 10^{6} \mathrm{~B}$ cells).

To determine whether a disproportionate percentage of B cells from SLE patients secreted anti-DNA or anti-TT antibody, we evaluated specific antibody production as a percentage of total Ig secretion. As shown in Fig. 5, the number of IgM anti-ssDNA antibody secreting cells constituted a mean of $1.6 \%$ and $1.8 \%$ of total IgM secreting cells in CD5+ and CD5$B$ cell subsets, respectively. IgG anti-ssDNA antibody secreting cells constituted $0.6 \%$ and $1.0 \%$ of total IgG secreting cells in CD5+ and CD5- B cell subsets, respectively. IgM anti-TT antibody secreting cells also constitute $0.9 \%$ of total IgM pro- 


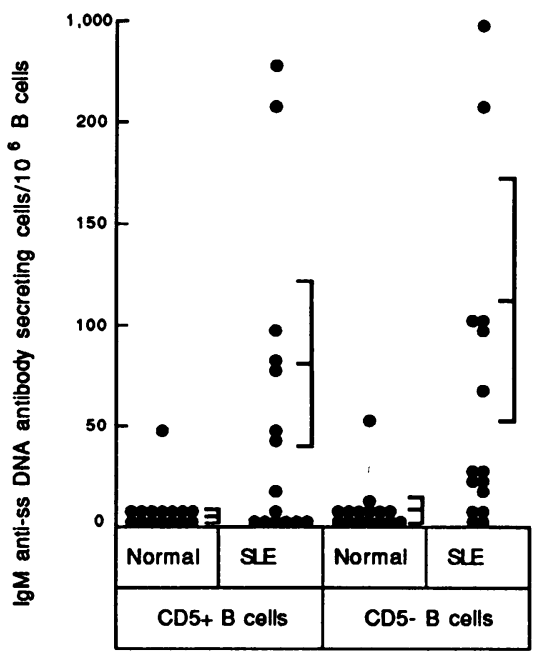

c

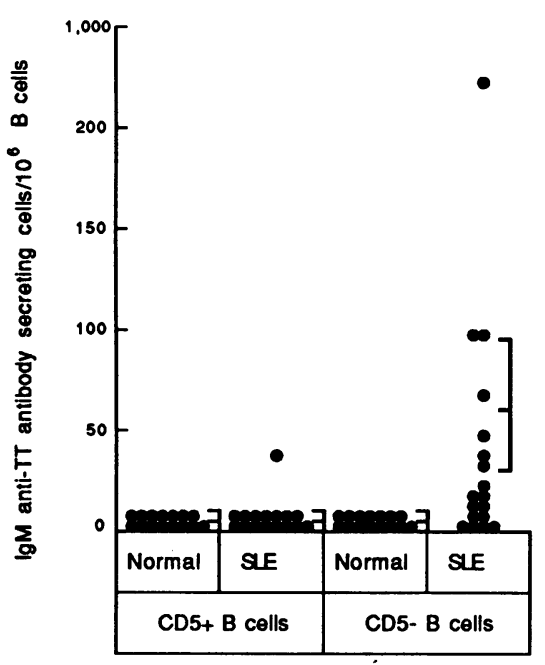

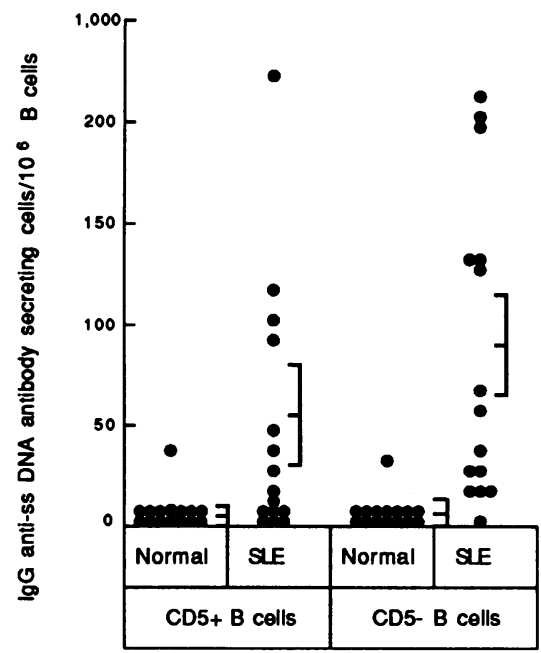

d

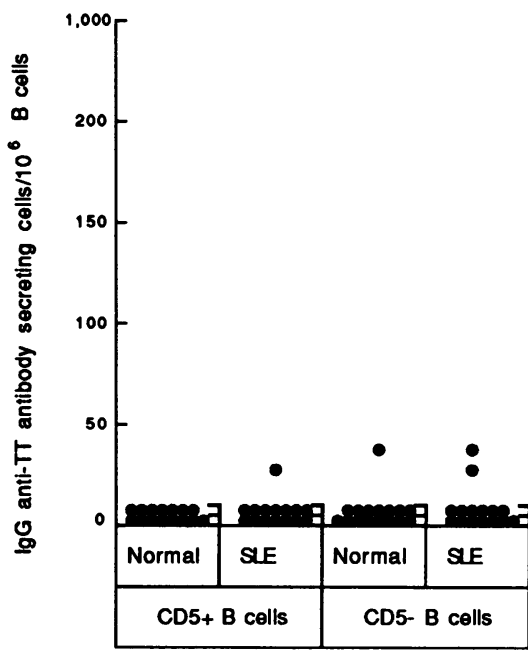

Figure 3. Spontaneous production of anti-ssDNA antibody and antitetanus toxoid (TT) antibody by SLE CD5+ B cells and CD5-B cells. Purified CD5+ or CD5- B cells from SLE patients as well as normal healthy control subjects were cultured for $18 \mathrm{~h}$ in wells coated with DNA or TT, and specific IgG and IgM producing cells were determined by ELIspot assay. (a) IgM anti-ssDNA antibody production, (b) IgG anti-ssDNA antibody production, (c) IgM anti-TT antibody production, (d) IgG antiTT antibody production. Brackets indicate mean \pm standard error of 15 SLE patients or 15 normal controls. ducing cells of the CD5- B cell subset in SLE patients. These average values are similar to those previously reported for lupus-prone mice (12), in which the proportion of B cells producing anti-DNA antibody, as a percentage of total Ig secreting cells, was $0.76 \%$ to $1.81 \%$ in various lupus-prone murine strains. However, in certain of our patients, anti-DNA antibody secreting cells constituted more than $5 \%$ of total Ig secreting cells (Fig. 5).

When individual patients were analyzed with respect to their cellular source of anti-ssDNA antibodies, four patterns were discernible (Table II): (a) patients whose CD5+ and CD5- B cells both produce anti-DNA antibody, $(b)$ patients who lack circulating anti-DNA antibody producing cells of either type, $(c)$ patients whose CD5- but not CD5+ B cells produce anti-DNA, and $(d)$ patients in whom CD5+ but not CD5- B cells produce anti-DNA. Although the first of these patterns was the most common $(n=7)$ and was associated with the highest levels of anti-DNA secreting cells, there were three patients whose CD5+ cells alone secreted anti-DNA, and another three patients whose CD5- cells alone secreted antiDNA. These results suggest that the cellular origin of antiDNA antibody is heterogeneous with respect to cell lineage (CD5+ vs. CD5-).

Drugs taken by SLE patients at the time of study, particularly corticosteroids, might have affected our results. However, there was no correlation between the level or the B cell source of anti-DNA and corticosteroid use in our patient cohort (Table I). Among those patients whose CD5+ and CD5- B cells both secreted anti-DNA, one was receiving $40 \mathrm{mg} / \mathrm{d}$ of prednisone at the time of study, one was receiving $15 \mathrm{mg} / \mathrm{d}$, two patients were receiving $10 \mathrm{mg} / \mathrm{d}$ and three were receiving no corticosteroids. This suggests that these doses of prednisone did not affect the cellular pattern of anti-DNA antibody production although the possibility exists that the absolute num- 


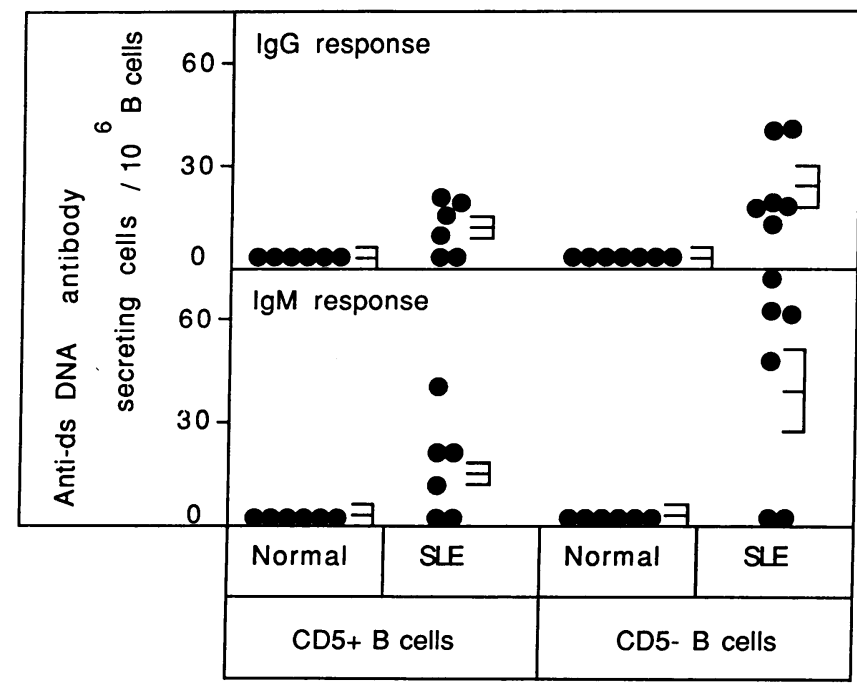

Figure 4. Spontaneous production of anti-double stranded (ds) DNA antibody from SLE and normal CD5+ and CD5- B cells. Spontaneous anti-dsDNA antibody production was measured by ELIspot assay as described in Methods. Each value represents the mean number of spots $/ 10^{6} \mathrm{~B}$ cells. Brackets indicate mean \pm standard error of six SLE patients or six normal control individuals.

bers of anti-DNA secreting cells might have been affected by treatment. These results are consistent with our previous finding that the levels of polyclonal Ig production in SLE patients is not correlated with corticosteroid use (21).

$S A C I$ induction of anti-DNA antibody production from $C D 5+$ and $C D 5-B$ cells. To examine the production of antiDNA antibody after a nonspecific in vitro stimulus, $2 \times 10^{5}$

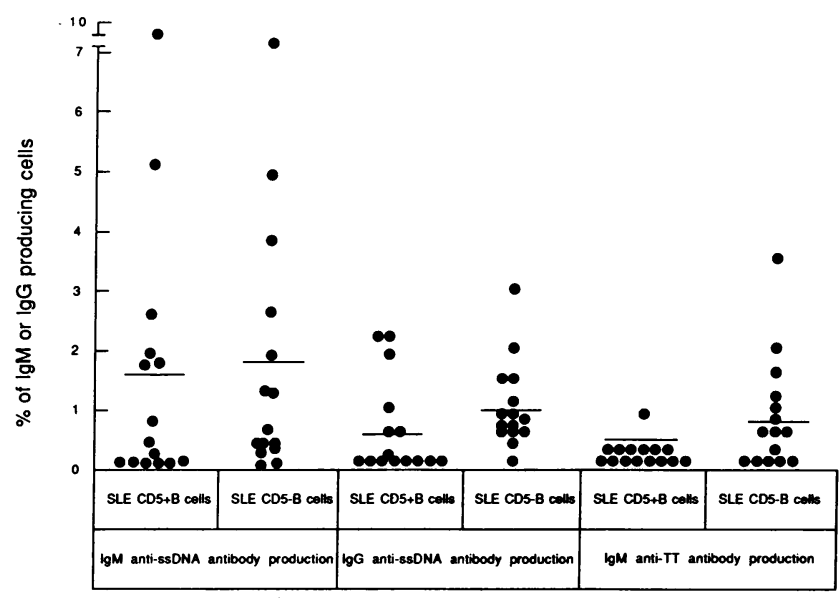

Figure 5. Relationship between the number of specific antibody producing and total Ig producing B cells in SLE patients. The number of spontaneous IgM or IgG anti-ssDNA or IgM anti-TT antibody-secreting cells and the total number of IgM- or IgG-secreting cells were determined as described in Methods for CD5+ and CD5- B cells from 15 SLE patients. The percentage of $B$ cells producing IgM specific for ssDNA (IgM anti-DNA), for example, was calculated by the following equation: number of IgM anti-DNA producing cells/number of IgM-producing cells $\times 100$. Bar indicates the mean percentage of 15 SLE patients.
Table II. Heterogeneity of Spontaneous Anti-ssDNA Antibody Producing B Cell Subpopulations from SLE Patients

\begin{tabular}{ccccccc}
\hline & & \multicolumn{2}{c}{ Anti-ssDNA antibody production (spots $/ 10^{6}$ B cells) } \\
\cline { 3 - 6 } & & \multicolumn{2}{c}{ IgM } & & \multicolumn{2}{c}{ IgG } \\
\cline { 3 - 6 } Pattern & $n$ & CD5+ B & CD5- B & CD5+ B & CD5- B \\
\hline 1 & 7 & $156 \pm 70$ & $217 \pm 113$ & $104 \pm 47$ & $115 \pm 34$ \\
2 & 2 & $<20$ & $<20$ & $<20$ & $<20$ \\
3 & 3 & $<20$ & $38 \pm 23$ & & $<20$ & $153 \pm 19$ \\
4 & 3 & $41 \pm 19$ & $<20$ & & $40 \pm 33$ & $<20$ \\
& & & & & &
\end{tabular}

Four cellular patterns of anti-ssDNA antibody production by SLE patients; pattern $1(n=7)$, both CD5+ and CD5-B cells secrete IgM and/or IgG anti-ssDNA antibody; pattern $2(n=2)$, neither subpopulation secretes anti-ssDNA antibody; pattern $3(n=3)$, CD5- B cells alone secrete IgM and/or IgG anti-ssDNA antibody; pattern $4(n$ $=3$ ), CD5+ B cells alone secrete IgM and/or IgG anti-ssDNA antibody. Each value represents the mean $\pm \mathrm{SE}$ of spots $/ 10^{6} \mathrm{~B}$ cells of each patient group.

CD5+ or CD5- B cells from SLE patients or healthy controls were stimulated with $0.002 \%$ SAC I in the presence of normal $T$ cell-derived helper factors, cultured for $6 \mathrm{~d}$, and then assayed for production of polyclonal Ig and anti-ssDNA antibody. As shown in Fig. 6, CD5+ as well as CD5- B cells from

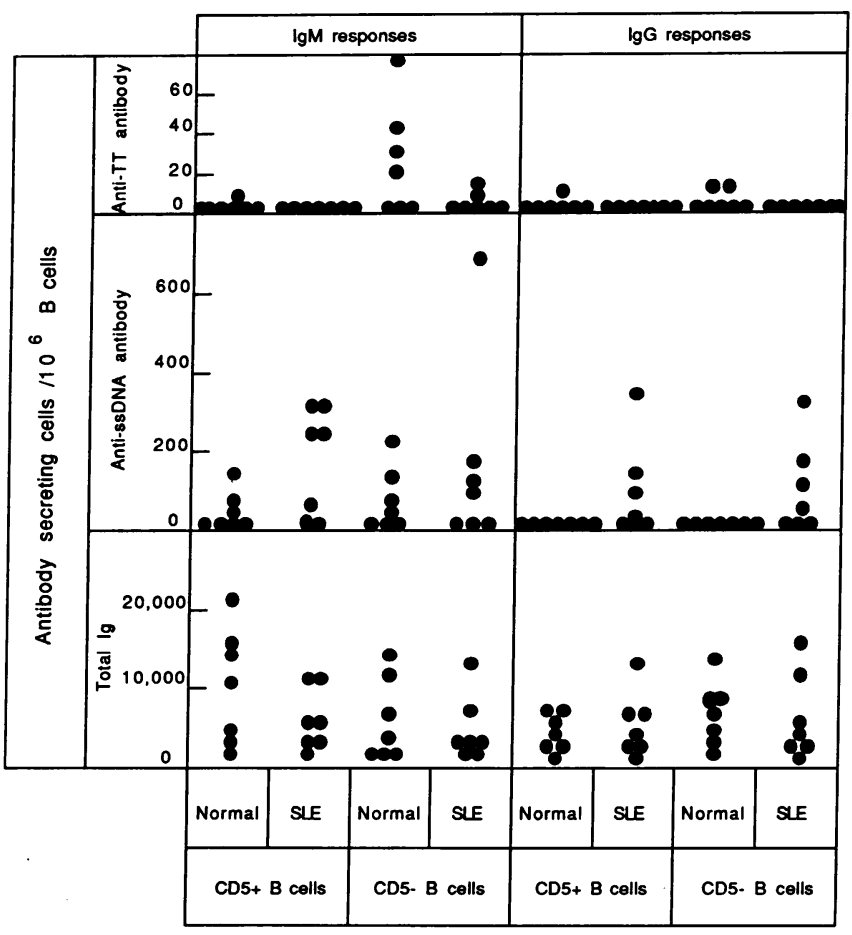

Figure 6. Induction of anti-DNA and anti-TT antibody production by Staphylococcus aureus Cowan $\mathrm{I}$ in combination with $\mathrm{T}$ cell helper factors. CD5+ and CD5- B cells from either SLE patients or normal controls were stimulated with $0.002 \%$ of Staphylococcus aureus Cowan I in the presence of $40 \% \mathrm{vol} / \mathrm{vol}$ normal T cell-derived helper factors, cultured for $6 \mathrm{~d}$, and assayed for polyclonal Ig production, anti-ssDNA antibody production and anti-TT antibody production. Each value represents the number of spots $/ 10^{6} \mathrm{~B}$ cells. 
both SLE patients and healthy control subjects produced IgM anti-DNA antibody upon stimulation with SAC I, IgG antiDNA antibody was produced only by the B cells of SLE patients. These results further support the notion that in human SLE both types of B cells produce anti-DNA antibody.

Relationship of spontaneous anti-DNA antibody production and polyclonal Ig production in SLE CD5+ and CD5-B cell subpopulations. In order to more directly examine the possible role of polyclonal $B$ cell activation in the production of antiDNA antibody in SLE, we next examined the relationship between spontaneous polyclonal Ig production and spontaneous anti-ssDNA antibody production for each B cell subpopulation. As shown in Fig. 7, $a$ and $c$, anti-DNA antibody production by CD5 + B cells occurred independently of polyclonal Ig production. Thus, some patients had very few anti-DNAsecreting CD5 + B cells despite large numbers of total (polyclonal) Ig secreting CD5+ B cells, whereas other patients with
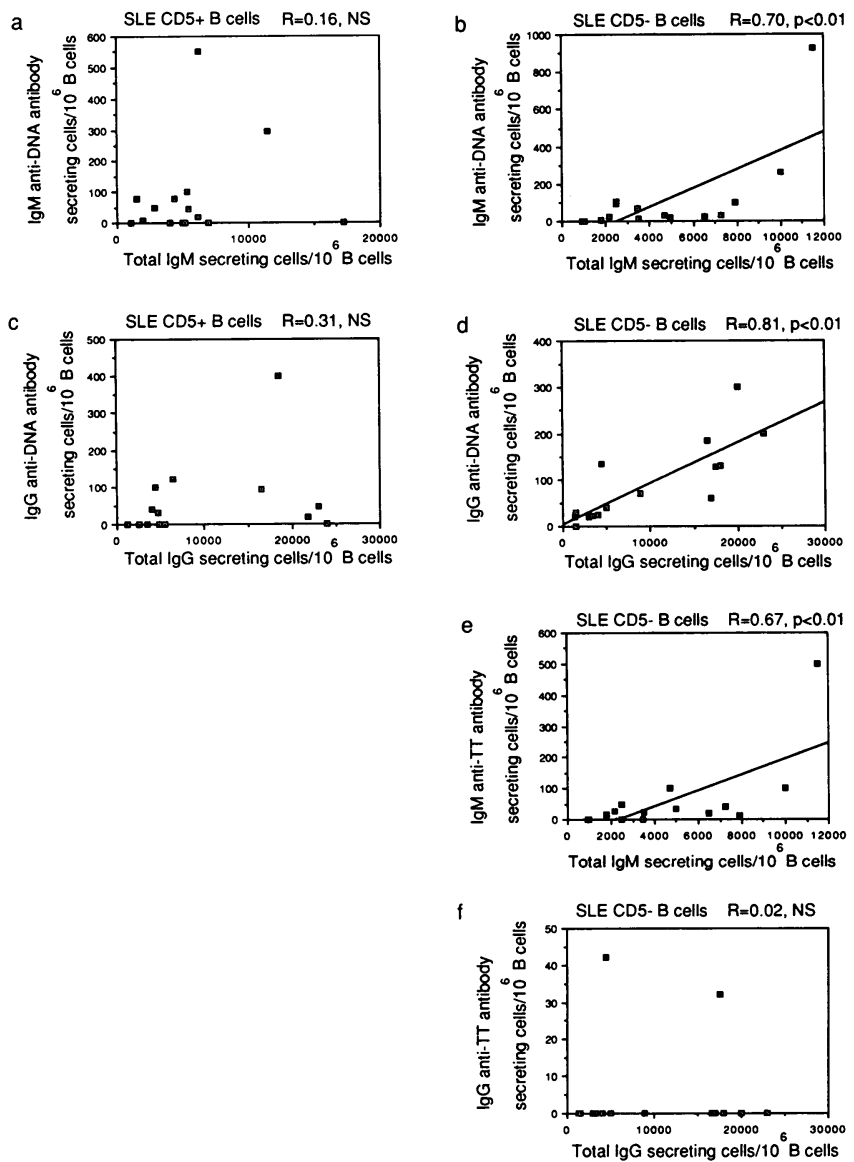

Figure 7. Relationship between spontaneous polyclonal Ig production and spontaneous anti-DNA antibody or anti-TT antibody production. (a) IgM anti-ssDNA antibody production and polyclonal IgM production within SLE CD5+ B cell subpopulation, $(b)$ those within SLE CD5- B cell subpopulation, (c) IgG anti-ssDNA antibody production and polyclonal IgG production within SLE CD5+ B cell subpopulation, $(d)$ those within SLE CD5- B cell subpopulation, (e) IgM anti-TT antibody production and polyclonal IgM production within SLE CD5- B cell subpopulation, $(f)$ IgG anti-TT antibody production and polyclonal IgG production of SLE CD5- B cell subpopulation. large numbers of anti-DNA producing CD5+ B cells had a relatively low number of polyclonal Ig secreting CD5 + B cells. This suggests that activation of anti-DNA antibody secreting CD5+ clones, in vivo, does not necessarily depend on polyclonal stimuli. In contrast to these findings, examination of the Ig secretion pattern of CD5- B cells reveals a strong correlation between polyclonal Ig production and anti-DNA antibody production (Fig. 7, $b$ and $d$ ), suggesting that anti-DNA antibody producing clones within the CD5- subpopulation were activated, in vivo, by polyclonal stimuli.

IgM anti-TT antibody production by CD5- B cells was also associated with polyclonal IgM production by the same cells (Fig. $7 e$ ). IgG anti-TT antibody was not associated with polyclonal IgG production; however, IgG anti-TT antibody was produced in very low frequency by only two patients (Fig. $7 f)$.

\section{Discussion}

In this study, a sensitive ELIspot assay was used to determine if the circulating B cells of patients with SLE spontaneously secrete anti-DNA antibody and, if so, whether CD5+ or CD5$B$ cells were the source of the antibody. Although there was substantial variation between patients, we found that CD5+ and/or CD5- B cells from the majority of SLE patients secreted both anti-ssDNA and anti-dsDNA antibody. In contrast, identically prepared B cell subpopulations from healthy subjects failed, with one exception, to secrete any detectable anti-DNA antibody.

CD5 + B cells have been reported previously to be a source of autoantibody production in mice as well as humans $(17,27$, $28,32,33)$. In addition, CD5 + B cells are the predominant source of anti-DNA antibody in murine models of SLE (17, 18). Therefore, our finding that CD5 + B cells from SLE patients secrete anti-DNA is not necessarily surprising and suggests, for the first time, that CD5+ B cells in SLE patients can spontaneously secrete autoantibody. However, in mice CD5+ $B$ cells produce mainly IgM antibodies whereas in this study human CD5+ B cells produced IgG as well as IgM antibodies. Moreover, in our SLE cohort there were more IgG than IgM antibody secreting CD5+ B cells (see Fig. 2). Casali et al. observed that normal human CD5+ B cells secreted IgG antibody to ssDNA upon activation with Epstein-Barr virus (28). Thus, while we do not yet know if CD5 + B cells secrete all IgG subclasses, it is clear that human CD5 + B cells can secrete IgG antibody, and this feature may distinguish human from mouse CD5+ B cells.

In contrast to CD5+ B cells, CD5- B cells have not been reported previously to produce anti-DNA or, to our knowledge, any other autoantibody. On this basis, our findings in human SLE appear to differ with previous findings in lupusprone mice $(17,18)$. The differences may reflect the lymphocyte sources examined; peripheral blood was analyzed in the present study, whereas spleen cells have been the major cell source studied in lupus mice. Alternatively, the mechanism responsible for anti-DNA production in human SLE may differ from that in murine models of SLE. Since humans are genetically heterogeneous, in contrast to the inbred mouse strains that develop lupus-like disease, the possibility exists that the pathogenesis of human SLE is also heterogeneous and 
varies among patients with otherwise similar clinical syndromes. Regardless of the precise explanation, the results rule out the notion that CD5+ B cells are the sole source of antiDNA antibody in human SLE.

These results not only suggest the existence of two antiDNA antibody producing B cell subsets in SLE but also raise the possibility that these subsets have different induction mechanisms. Thus, the levels of anti-DNA antibody secretion by CD5- B cells correlated closely with the level of polyclonal Ig production by the same subpopulation. In contrast, antiDNA production by CD5+ B cells was independent of polyclonal Ig secretion by either this subpopulation or CD5- B cells (Fig. 7, $a$ and $c$ and data not shown). We interpret these findings to suggest that a polyclonal stimulus is responsible for the production of anti-DNA antibody by CD5- B cells, whereas a more selective stimulus is responsible for anti-DNA production by $\mathrm{CD} 5+\mathrm{B}$ cells. Although a recent study of CD5+ B cells in NZB/NZW F1 mice has suggested that these cells may be subject to antigen-induced clonal selection (47), the stimulus responsible for the preferential activation of antiDNA secreting CD5+ B cells in human SLE is unknown. If the repertoire of $\mathrm{CD} 5+\mathrm{B}$ cells is highly restricted, the same polyclonal stimulus could conceivably be responsible for the activation of $\mathrm{CD} 5+$ as well as CD5- B cells.

The underlying stimulus responsible for autoantibody production in SLE has been debated for many years. One model to account for autoantibody generation suggests that self-specific antibodies are encoded by germ line $\mathrm{V}$ gene repertoire (48) and are thus present in both normal and diseased individuals. In normal individuals, self-reactive cells are suppressed, but in disease, an abnormal polyclonal B cell activation may occur resulting in the pathological secretion of autoantibodies $(24,49-51)$. This model predicts that autoantibodies would resemble those derived after polyclonal activation of normal $B$ cells. A second model invokes self-antigens, not polyclonal activation, as the driving force for the production of autoantibodies $(14,52-54)$. This antigen driven model predicts that autoantibodies would resemble antibodies produced during the secondary immune response to foreign antigens; these are usually derived from clonally related precursors, somatically mutated (often reflecting selection of mutations by antigens), and isotype switched $(55,56)$.

It is possible that both antigen specific and polyclonal B cell activation contribute independently to the hypergammaglobulinemia and autoantibody production found in SLE patients. Alternatively, the presence of a factor capable of inducing polyclonal B cell activation in conjunction with low levels of antigen (or autoantigen) could induce the preferential proliferation of $B$ cells reactive with that antigen. The current study suggests that polyclonal activation of $B$ cells and preferential activation of autoantibody producing clones are not mutually exclusive; rather, both mechanisms may contribute to the formation of anti-DNA antibody in SLE patients. A similar combined model of autoimmunity was proposed recently by Dziarski and Klinman et al. $(57,58)$.

Recent studies suggest that autoantibodies, such as rheumatoid factor and anti-DNA antibody, differ from one another in their affinity for antigen depending on the Ig $\mathrm{V}$ genes that encode them. Some rheumatoid factors, for example, are cross-reactive low affinity autoantibodies encoded by germ line $\mathrm{V}$ genes $(32,57)$, while others are of high affinity, harbor numerous somatic mutations and resemble antibodies elicited by exogenous antigens after secondary immunization (59-61). In this regard, it will be of interest to determine whether the anti-DNA antibodies produced by CD5+ and CD5- B cells differ in affinity and/or $V$ gene usage. Of course, it will be of no less importance to determine the possible contribution of anti-DNA antibody produced by CD5+ and CD5- B cells to the clinical manifestation of SLE.

\section{Acknowledgments}

The authors gratefully acknowledge the assistance of Claudia Benike, who provided helpful discussion, and Donna Jones, who provided superb secretarial support.

This work was supported, in part, by grant CA-24607 from the National Institutes of Health.

\section{References}

1. Theofilopoulos, A. N., and F. J. Dixon. 1985. Murine models of systemic lupus erythematosus. Adv. Immunol. 37:269-390.

2. Zvaifler, N. J. 1981. Etiology and pathogenesis of systemic lupus erythematosus. In Textbook of Rheumatology. Vol. II. W. N. Kelly, E. D. Harris, S. Ruddy, and C. B. Sledge, editors. W. B. Saunders, Inc., Philadelphia, PA. 1079-1105.

3. Smith, H. R., and A. D. Steinberg. 1983. Autoimmunity: a perspective. Annu. Rev. Immunol. 1:175-210.

4. Delfraissy, J. F., P. Segond, P. Gelanaud, C. Walland, P. Massias, and J. Dormon. 1980. Decreased primary in vitro antibody response in untreated systemic lupus erythematosus: $T$ helper cell defect and lack of defective suppressor cell function. J. Clin. Invest. 66:141-148.

5. Abdou, N. I., A. Sagawa, E. Pascual, J. Herbert, and S. Sadhegee. 1976. Suppressor T cell abnormality in idiopathic systemic lupus erythematosus. Clin. Immunol. Immunopathol. 6:192-199.

6. Fauci, A. S., A. D. Steinberg, B. F. Haynes, and G. Whalen. 1978. Immunoregulatory aberrations in systemic lupus erythematosus. J. Immunol. 121:1473-1479.

7. Sakane, T., S. Takada, N. Suzuki, Y. Tsuchida, Y. Murakawa, and $Y$. Ueda. 1986. Deficiencies in suppressor $T$ cell activity seen in patients with active systemic lupus erythematosus are due to the dilution of normally functioning suppressor $T$ cells by the nonsuppressor $T$ cells. J. Immunol. 137:3809-3813.

8. Morimoto, C., A. D. Steinberg, N. L. Letvin, M. Hagan, T. Takeuchi, J. Daley, H. Levine, and S. F. Schlossman. 1987. A defect of immunoregulatory $T$ cell subsets in systemic lupus erythematosus patients demonstrated with anti-2H4 antibody. J. Clin. Invest. 79:762768.

9. Hardin, J. A. 1986. The lupus autoantigens and the pathogenesis of systemic lupus erythematosus. Arthritis Rheum. 24:457-460.

10. Izui, S., P. J. McConahey, and F. J. Dixon. 1978. Increased spontaneous polyclonal activation of B lymphocytes in mice with spontaneous autoimmune disease. J. Immunol. 121:2213-2219.

11. Prud'homme, G. J., R. S. Balderas, F. J. Dixon, and A. N. Theofilopoulos. 1983. B cell dependence on and response to accessory signals in murine lupus strains. J. Exp. Med. 157:1815-1827.

12. Klinman, D. M., and A. D. Steinberg. 1987. Systemic autoimmune disease arises from polyclonal B cell activation. J. Exp. Med. 165:1755-1760.

13. Portanova, J. P., H. N. Claman, and B. L. Kotzin. 1985. Autoimmunization in murine graft-vs-host disease. I. Selective production of antibodies to histone and DNA. J. Immunol. 135:3850-3856.

14. Gharavi, A. E., J.-L. Chu, and K. B. Elkon. 1988. Autoantibodies to intracellular proteins in human systemic lupus erythematosus are not due to random polyclonal B cell activation. Arthritis Rheum. 31:1337-1345. 
15. Klinman, D. M., and A. D. Steinberg. 1986. Proliferation of anti-DNA producing NZB B cells in non-autoimmune environment. J. Immunol. 137:69-75.

16. Gleichmann, E., S. T. Pals, A. G. Rolink, T. Radaszkiewicz, and $H$. Gleichmann. 1984. Graft-versus-host reaction: clues to the etiopathology of a spectrum of immunological diseases. Immunol. Today. 5:324-331.

17. Hayakawa, K., R. R. Hardy, M. Honda, L. A. Herzenberg, A. D. Steinberg, and L. A. Herzenberg. 1984. Ly1 B cells: functionally distinct lymphocytes that secrete IgM antibodies. Proc. Natl. Acad. Sci. USA. 81:2494-2498.

18. Hayakawa, K., R. R. Hardy, L. A. Herzenberg, and L. A. Herzenberg. 1985. Progenitors for Ly-1 B cells are distinct from progenitors for other B cells. J. Exp. Med. 1554-1568.

19. Budman, D. R., E. B. Merchant, A. D. Steinberg, B. Doft, M. E. Gershwin, E. Lizzio, and J. P. Reeves. 1977. Increased spontaneous activity of antibody-forming cells in the peripheral blood of patients with active SLE. Arthritis Rheum. 20:829-833.

20. Ginsberg, W. W., F. D. Finkelman, and P. E. Lipsky. 1979. Circulating and pokeweed mitogen-induced immunoglobulin-secreting cells in systemic lupus erythematosus. Clin. Exp. Immunol. 35:76-88.

21. Sakane, T., N. Suzuki, S. Takada, Y. Ueda, Y. Murakawa, T. Tsuchida, Y. Yamauchi, and T. Kishimoto. 1988. B cell hyperactivity and its relation to distinct clinical features and the degree of disease activity in patients with systemic lupus erythematosus. Arthritis Rheum. 31:80-87.

22. Fish, F., and M. Ziff. 1982. The in vitro and in vivo induction of anti-double-stranded DNA antibodies in normal and autoimmune mice. J. Immunol. 128:409-414.

23. Dziarski, R. 1984. Anti-immunoglobulin autoantibodies are not preferentially induced in polyclonal activation of human and mouse lymphocytes, and more anti-DNA and anti-erythrocyte autoantibodies are induced in polyclonal activation of mouse than human lymphocytes. J. Immunol. 133:2537-2544.

24. Hang, L., J. H. Slack, C. Amundson, S. Izui, A. N. Theofilopoulos, and F. J. Dixon. Induction of murine autoimmune disease by chronic polyclonal B cell activation. J. Exp. Med. 157:874-883.

25. Chused, T. M., K. L. McCoy, R. B. Lal, E. M. Brown, and P. J. Baker. 1987. Multigenic basis of autoimmune disease in New Zealand Mice. Concepts Immunopathol. 4:129-143.

26. Gadol, N., and K. A. Ault. 1986. Phenotypic and functional characterization of human Leu 1 (CD5) B cells. Immunol. Rev. 93:23-34.

27. Hardy, R. R., H. Hayakawa, M. Shimizu, K. Yamasaki, and T. Kishimoto. 1987. Rheumatoid factor secretion from human Leu 1+ B cells. Science (Wash. DC). 236:81-83.

28. Casali, P., S. E. Burastero, M. Nakamura, G. Inghirami, and A. L. Notkins. 1987. Human lymphocytes making rheumatoid factor and antibody to ssDNA belong to Leu-1+ B-cell subset. Science (Wash. DC). 236:77-81.

29. Kipps, T. J., and J. H. Vaughan. 1987. Genetic influence on the levels of circulating CD5 B lymphocytes. J. Immunol. 139:1060-1064.

30. Antin, J. H., S. G. Emerson, P. Martin, N. Gadol, and K. A. Ault. 1986. Leu-1+ (CD5+) B cells: a major lymphoid subpopulation in human fetal spleen: phenotypic and functional studies. J. Immunol. 136:505-510.

31. Richard, Y., C. Leprince, B. Dugas, D. Treton, and P. Galanaud. 1987. Reactivity of Leu-1+ tonsillar B cells to a high molecular weight B cell growth factor. J. Immunol. 139:1563-1567.

32. Nakamura, N., S. E. Burastero, A. L. Notkins, and P. Casali. 1988. Human monoclonal rheumatoid factor-like antibodies from CD5 (Leu-1)+ B cells are polyreactive. J. Immunol. 140:4180-4186.

33. Hardy, R. R., and K. Hayakawa. 1986. Development and physiology of Ly-1B and its human homolog, Leu-1B. Immunol. Rev. 93:53-79.

34. Taniguchi, O., H. Miyajima, T. Hirano, M. Noguchi, A. Ueda,
H. Hashimoto, S. Hirose, and K. Okumura. 1987. The Leu-1 B-cell subpopulation in patients with rheumatoid arthritis. J. Clin. Immunol. 7:441-448

35. Tan, E. M., A. S. Cohen, J. F. Fries, A. T. Masi, D. J. McShane, N. F. Rothfield, J. G. Schaller, N. Talal, and R. J. Winchester. 1982. The 1982 revised criteria for the classification of systemic lupus erythematosus. Arthritis Rheum. 25:1271-1277.

36. Suzuki, N., and T. Sakane. 1989. Induction of excessive B cell proliferation and differentiation by an in vitro stimulus in culture in human systemic lupus erythematosus. J. Clin. Invest. 83:937-944.

37. Suzuki, N., Y. Ueda, and T. Sakane. 1988. Differential mechanism for differentiation into immunoglobulin secreting cells in human resting B lymphocyte subsets isolated on the basis of cell density. $J$. Clin. Invest. 81:261-269.

38. Suzuki, N., T. Sakane, Y. Ueda, Y. Murakawa, and T. Tsunematsu. 1986. Implications for the role of cognate interactions in in vitro human B cell activation by Staphylococcus aureus Cowan I and pokeweed mitogen. J. Clin. Invest. 77:294-300.

39. Engleman, E. G., C. J. Benike, F. C. Grumet, and R. L. Evans. 1981. Activation of human $T$ lymphocyte subsets: helper and suppressor/cytotoxic cell recognize and resond to distinct histocompatibility antigens. J. Immunol. 127:2124-2129.

40. Locker, J. D., M. E. Medof, R. M. Bennett, and S. Sukhupunyaraka. 1977. Characterization of DNA used to assay sera for antiDNA antibodies; determination of the specificities of anti-DNA antibodies in SLE and non-SLE rheumatic disease states. J. Immunol. 118:694-701.

41. Rivas, A., J. Koide, M. Cleary, and E. G. Engleman. 1989. Evidence for involvement of the $\gamma, \delta \mathrm{T}$ cell antigen receptor in cytotoxicity mediated by human alloantigen specific $\mathrm{T}$ cell clones. $\mathrm{J}$. Immunol. 146:1840-1846.

42. Sedgwick, J. D., and P. G. Holt. 1983. A solid-phase immunoenzymatic technique for the enumeration of specific antibody-secreting cells. J. Immunol. Methods. 57:301-309.

43. Ando, D., F. M. Ebling, and B. H. Hahn. 1986. Detection of native and denatured DNA antibody forming cells by the enzymelinked immunospot assay: a clinical study of (New Zealand black $\times$ New Zealand white) F1 mice. Arthritis Rheum. 29:1139-1146.

44. Logtenberg, T., M. Jonker, A. Kroon, F. H. J. Gmelig-Meyling, and R. E. Ballieux. 1985. Enumeration of (auto)antibody producing cells in human using the "spot-ELISA." Immunol. Lett. 9:343-347.

45. Logtenberg, T., M. B. Pernella, A. Kroon, F. H. J. GmeligMeyling, and R. E. Ballieux. 1988. Autoreactive B cells in normal humans: autoantibody production upon lymphocyte stimulation with autoantigen-xenoantigen conjugates. J. Immunol. 140:446-450.

46. Eaton, R. B., G. Schneider, and P. H. Schur. 1983. Enzyme immunoassay for antibodies to native DNA: specificity and quality of antibodies. Arthritis Rheum. 26:52-62.

47. Tarlinton, D., A. M. Stall, and L. A. Herzenberg. 1988. Repetitive usage of immunoglobulin VH and D gene segments in CD5+ Ly-1 B clones of $(\mathrm{NZB} \times \mathrm{NZW}) \mathrm{Fl}$ mice. EMBO (Eur. Mol. Biol. Organ.) J. 7:3705-3710.

48. Sanz, I., H. Dang, M. Takei, N. Talal, and J. D. Capra. 1989. VH sequence of a human anti-Sm autoantibody: evidence that autoantibodies can be unmutated copies of germline genes. J. Immunol. 142:883-887.

49. Dziarski, R. 1982. Preferential induction of autoantibody secretion in polyclonal activation by peptidoglycan and lipopolysaccharide. J. Immunol. 128:1018-1025.

50. Teodorescu, M. 1981. Characterization and role in autoimmune diseases of the polyclonal B-cell activator produced by T-cellsthe helper factor. Immunol. Rev. 55:155-178.

51. Theofilopoulos, A. N., D. L. Shawler, R. A. Eisenberg, and F. J. Dixon. 1980. Splenic immunoglobulin-secreting cells and their regulation in autoimmune mice. J. Exp. Med. 151:446-466.

52. Shores, E. A., R. A. Eisenberg, and P. L. Cohen. 1986. Role of 
the Sm antigen in the generation of anti-Sm autoantibodies in the SLE-prone MRL mouse. J. Immunol. 136:3662-3667.

53. Van Der Veen, R. F. M. 1984. Further evidence against random polyclonal antibody formation in mice with lupus-like graft-vshost disease. J. Immunol. 132:1814-1819.

54. Nelson, J. L., F. A. Nardella, R. I. Opplinger, and M. Mannick. 1987. Rheumatoid factors from patients with rheumatoid arthritis possess private repertoires of idiotypes. J. Immunol. 138:1391-1396.

55. Clarke, S. H., K. Huppi, D. Ruezinsky, L. Staudt, W. Gerhard, and $M$. Weigert. 1985. Inter- and intraclonal diversity in the antibody response to influenza hemagglutinin. J. Exp. Med. 161:687-704.

56. Caton, A., G. G. Brownlee, L. M. Staudt, and W. Gerhard. 1986. Structural and functional implications of a restricted antibody response to a defined antigenic region on the influenza virus hemagglutinin. EMBO (Eur. Mol. Biol. Organ.) J. 5:1577-1587.

57. Dziarski, R. 1988. Autoimmunity: polyclonal activation or antigen induction? Immunol. Today. 9:340-342.
58. Klinman, D. M., Y. Ishigatsubo, and A. D. Steinberg. 1988. Acquisition and maturation of expressed B cell repertoires in normal and autoimmune mice. J. Immunol. 141:801-806.

59. Shlomchik, M. J., A. Marshak-Rothstein, C. B. Wolfowicz, T. L. Rothstein, and M. G. Weigert. 1987. The role of clonal selection and somatic mutation in autoimmunity. Nature (Lond.). 328:805811 .

60. Shlomchik, M. J., A. H. Aucoin, D. S. Pisetsky, and M. G. Weigert. 1987. Structure and function of anti-DNA autoantibodies derived from a single autoimmune mouse. Proc. Natl. Acad. Sci. USA. 84:9150-9154.

61. Nakamura, M., S. E. Burastero, Y. Ueki, J. W. Larrick, A. L. Notkins, and P. Casali. 1988. Probing the normal and autoimmune B cell repertoire with Epstein-Barr virus: frequency of B cells producing monoreactive high affinity autoantibodies in patients with Hashimoto's disease and systemic lupus erythematosus. J. Immunol. $141: 4165-4172$. 